\title{
Intergenerational Transfers, Lifetime Welfare and Resource Preservation
}

\section{Journal Article}

Author(s):

Valente, Simone

Publication date:

2008

Permanent link:

https://doi.org/10.3929/ethz-b-000006105

Rights / license:

In Copyright - Non-Commercial Use Permitted

Originally published in:

Environment and Development Economics 13(1), https://doi.org/10.1017/S1355770X07004068 


\title{
Intergenerational transfers, lifetime welfare, and resource preservation*
}

\author{
SIMONE VALENTE \\ Center of Economic Research, ETH Zurich. \\ Email:svalente@ethz.ch
}

\begin{abstract}
This paper analyzes overlapping-generations models where natural capital is owned by selfish agents. Transfers in favor of young agents reduce the rate of depletion and increase output growth. It is shown that intergenerational transfers may be preferred to laissez-faire by an indefinite sequence of generations: if the resource share in production is sufficiently high, the welfare gain induced by preservation compensates for the loss due to taxation. This conclusion is reinforced when other assets are available, e.g. man-made capital, claims on monopoly rents, and R\&D investment. Transfers raise the welfare of all generations, except that of the first resource owner: if resource endowments are taxed at time zero, all successive generations support resource-saving policies for purely selfish reasons.
\end{abstract}

\section{Introduction}

Preserving intergenerational equity has become a worldwide political concern, and achieving sustainability is increasingly considered a relevant social goal. As over-exploitation represents a threat for the ability of future generations to meet their own needs, a major source of intergenerational conflict is represented by the intensive use of natural resources in the production process. Since Hotelling's (1931) seminal work, economists have pointed out several potential sources of the problem: over-exploitation may result from market incompleteness, excessive competition, myopic behavior, and the lack of incentives for investment in preservation. Accordingly, public intervention may be called for either to restore efficiency

\footnotetext{
* The bulk of this paper was written while visiting CentER, Tilburg University. I owe special thanks to Cees Withagen for insightful comments, and three anonymous referees for useful suggestions. I also thank Lucas Bretschger, Christa Brunnschweiler, Hannes Egli, Karen Pittel, Andreas Schäfer, and seminar participants at the Swiss Society of Economics and Statistics Annual Meeting (2005). Financial support from the European Commission - Marie Curie Fellowships is gratefully acknowledged.
} 
(Toman, 1987) or settle conflicts between intertemporal efficiency and intergenerational fairness (Howarth and Norgaard, 1990). ${ }^{1}$

In recent times, the attribution of property rights over natural resources has gained much attention in the policy debate. However, neither sustainability nor resource preservation are guaranteed when natural capital is private property. This result holds in general equilibrium models with infinitely lived agents (Pezzey, 1992), and is furthermore valid when assuming selfish agents with finite lifetimes (Mourmouras, 1993): market valuation of resource assets can only limit the depletion rate to the extent that preserving natural capital is profitable to agents currently alive. Consequently, achieving intergenerational fairness requires a system of transfers that redistributes income among generations: examples in the recent literature on resource economics include Howarth (1991), Mourmouras (1993), Krautkraemer and Batina (1999), Gerlagh and Keyzer (2001). The logic underlying these contributions is that of pursuing intergenerational fairness while preserving intertemporal efficiency, and this typically implies considering lump-sum transfers. However, the welfare effects of transfers can also be investigated from a different perspective, which is alternative to (but not conflicting with) the efficiency-and-equity logic. Real-world policymaking is often constrained by institutional feasibility: lump-sum taxes have a limited application, and policies involving intergenerational transfers likely need the support of the constituency. Building on this point, this paper poses the following question. Consider an economy with overlapping generations where natural capital is essential for production. Suppose that, under laissez-faire conditions, the economy displays unsustainability - i.e. utility of future generations will be lower than current welfare levels. Would selfish agents agree on a system of intergenerational transfers implying a lower rate of resource extraction?

Postulating a direct link between political support and individual welfare, this paper tackles the issue by characterizing individual payoffs in a regime-contingent fashion - that is, lifetime utility levels of a given generation under alternative policy regimes - assuming that transfers are implemented through distortionary measures. The crucial result is that a higher degree of resource preservation may be strictly preferred by private agents, provided that a critical condition on technological parameters is satisfied. More precisely, it is shown that if the resourceshare in production is sufficiently high, taxing natural capital incomes to subsidize young generations guarantees higher lifetime utility for all newborn generations. The reason for this result is that a lower rate of depletion increases the growth rate of the economy in the subsequent period: if resource productivity is sufficiently high, this positive effect on second-period income more than compensates for the negative effect of taxation, and agents will prefer non-zero transfers to laissez-faire conditions

${ }^{1}$ Bromley (1990) forcefully argues that environmental policy should not be restricted to efficiency targets. In line with this view is the idea that sustainability is a matter of intergenerational equity and, once the social objective incorporates fairness concerns, efficiency per se does not guarantee socially optimal outcomes (Howarth and Norgaard, 1990). 
for purely selfish reasons. Moreover, this mechanism is enhanced by the presence of other assets representing individual wealth. Extending the model to include man-made capital, monopoly rents, and R\&D sectors, it is shown that the critical condition becomes less restrictive because the returns from these assets also benefit from the positive growth effect induced by a higher degree of preservation.

From a policymaking perspective, the private desire for resource-saving policies unfolds if young generations are credibly pre-committed. In this regard, it is shown that permanent transfers may arise as an indefinite sequence of lifetime contracts: if young agents were asked to choose between permanent transfers and permanent laissez-faire, the former option would be preferred. In the absence of commitment devices, transfers may arise as political equilibria in sequential voting games when young agents have majority power or old agents are induced to cooperate by the presence of regime-switching costs. In all the above cases, the intergenerational distribution of benefits under resource-saving policies is not Pareto comparable with that obtained under laissez-faire, since resource owners at time zero bear the burden of initial taxation: similarly to Gale (1973), if the first resource owner partially renounces his claim over initial endowments, the transmission of this credit forward in time yields welfare gains for all successive generations.

\section{The basic model}

In line with recent literature, a sustainable path is defined as a path along which welfare is non-declining over time. ${ }^{2}$ The economy has an overlapping-generations structure: each agent lives for two periods, and enjoys utility from consumption when young (c) and consumption when old (e). Population in period $t$ consists of $N_{t}$ young and $N_{t-1}$ old individuals, with a constant rate $n$ of population growth: $N_{t+1}=N_{t}(1+n)$. Denoting by $U_{t}$ the lifetime utility of an agent born in period $t$, sustainability requires

$$
U_{t+1}\left(c_{t+1}, e_{t+2}\right) \geq U_{t}\left(c_{t}, e_{t+1}\right), \quad \forall t \in[0, \infty) .
$$

Denoting by $R_{t}$ the stock of natural resources available in the economy, we also define no depletion paths as those paths satisfying

$$
R_{t+1} \geq R_{t}, \quad \forall t \in[0, \infty) .
$$

Our formal analysis draws on Mourmouras (1993) and Krautkraemer and Batina (1999): in this section, we augment the Mourmouras (1993) model by considering exogenous technical progress; further extensions regarding man-made capital, monopoly rents and endogenous technical change are developed later in section 4 . Prospects for sustainability and natural preservation depend on the intergenerational distribution of entitlements,

2 This definition of sustainability may be referred to as the concept of 'sustained development', as defined e.g. in Pezzey (1997). Recent formal literature considers non-declining utility a pre-requisite for sustainable development, although sustainability in this broader sense is nowadays referred to in the presence of global environmental problems (such as climate change and biodiversity loss) that are not considered in the present analysis. 
which affect the time-path of resource use, and, in turn, the production frontier and consumption possibilities of generations yet to be born. In this regard, we assume a grandfathering process à la Krautkraemer and Batina (1999): at the beginning of period $t$, the whole stock of natural resources in the economy $R_{t}$ is held by old agents. Part of $R$ is used as natural capital in production $(X)$, while the remaining stock constitutes resource assets $(A)$

$$
R_{t}=A_{t}+X_{t}
$$

Old agents sell resource assets $A_{t}$ to young agents at unit price $q_{t}$, and receive a gross marginal rent $p_{t}$ for each unit of natural capital $X_{t}$ supplied to firms. Quantities of resource assets and natural capital per young individual are denoted by $a_{t}=A_{t} / N_{t}$ and $x_{t}=X_{t} / N_{t}$, respectively. While natural capital is destroyed in the production process, resource assets sold to newborn generations are brought forward in time: in each period, the resource grows at constant regeneration rate $\varepsilon$, implying

$$
R_{t+1}=(1+\varepsilon)\left(R_{t}-X_{t}\right)=(1+\varepsilon) A_{t} .
$$

Only young agents work, supplying one unit of labor services. The consumption good is produced by means of natural capital and labor, according to technology

$$
\begin{aligned}
Y_{t} & =\left(m_{t} X_{t}\right)^{\alpha}\left(N_{t}\right)^{1-\alpha}, \\
m_{t} & =m_{t-1}(1+\delta),
\end{aligned}
$$

where $Y_{t}$ is aggregate output, $N_{t}$ equals total labor units supplied by the currently young, and $m_{t}$ is the state of technology, representing a process that enhances the productivity of natural capital in each period: $\delta>0$ is the rate of resource-augmenting technological progress. ${ }^{3}$ Denoting by $w$ the wage rate, profit maximization implies

$$
\begin{aligned}
p_{t} & =\alpha y_{t} x_{t}^{-1}=\alpha m_{t}^{\alpha} x_{t}^{\alpha-1}, \\
w_{t} & =(1-\alpha) y_{t}=(1-\alpha) m_{t}^{\alpha} x_{t}^{\alpha},
\end{aligned}
$$

where $y_{t}=Y_{t} / N_{t}$ is output per worker. Intergenerational transfers take the following form: young agents' investment is subsidized by taxing the income from natural capital of old agents, and fiscal authorities keep a balanced budget in each period. Formally,

$$
\begin{aligned}
c_{t} & =w_{t}-q_{t}\left(1-d_{t}\right) a_{t}, \\
e_{t+1} & =\left[p_{t+1}\left(1-\tau_{t+1}\right) x_{t+1}+q_{t+1} a_{t+1}\right](1+n), \\
p_{t} \tau_{t} X_{t} & =q_{t} d_{t} A_{t} \\
y_{t} & =c_{t}+e_{t}(1+n)^{-1} .
\end{aligned}
$$

${ }^{3}$ In general, technical progress in Cobb-Douglas technologies is input neutral, and (5) may be rewritten as $Y=X^{\alpha} L^{1-\alpha} \hat{m}$, where the growth rate of $\hat{m}=m^{\alpha}$ is the Hicks-neutral rate of technical progress. Specification (5) is chosen to emphasize that prospects for sustainability depend on the resource-saving effect of technical progress $\left(m_{t+1} / m_{t}\right)$, and not on its global effect on output levels $\left(\hat{m}_{t+1} / \hat{m}_{t}\right)-$ see Proposition 1. 
Equations (9) and (10) represent budget constraints faced by each individual born in period $t$, where $d$ is the subsidy rate on investment in resource assets, and $\tau$ is the tax rate on natural capital income. Equation (11) is the government budget constraint, and equation (12) is the aggregate constraint of the economy. Agents are homogeneous and have logarithmic preferences: lifetime utility is $U_{t}=\log c_{t}+\beta \log e_{t+1}$, where $\beta \in(0,1)$ is the individual discount factor. Equilibrium in the resource market requires

$$
q_{t}=p_{t}\left(1-\tau_{t}\right)
$$

in each period. The consumer problem consists of choosing $c_{t}$ and $e_{t+1}$ in order to maximize lifetime utility subject to (9)-(10): first-order conditions read

$$
\frac{e_{t+1}}{\beta c_{t}}=\frac{q_{t+1}(1+\varepsilon)}{q_{t}\left(1-d_{t}\right)} .
$$

The temporary equilibrium of the economy is characterized by the following relations: ${ }^{4}$ the natural capital-resource asset ratio $(z)$ equals

$$
z_{t} \equiv \frac{x_{t}}{a_{t}}=\frac{\alpha(1+\beta)}{\beta(1-\alpha)}\left(1-\tau_{t}\right)\left(1-d_{t}\right),
$$

and the dynamics of the economy are described by

$$
\begin{aligned}
\theta_{t+1}^{R} & =\frac{1+\varepsilon}{1+z_{t}}, \\
\theta_{t+1}^{x} & =\frac{z_{t+1}(1+\varepsilon)}{z_{t}\left(1+z_{t+1}\right)(1+n)}, \\
\theta_{t+1}^{y} & =\left[\frac{z_{t+1}(1+\rho)}{z_{t}\left(1+z_{t+1}\right)}\right]^{\alpha},
\end{aligned}
$$

where $\theta_{t+1}^{v}=\left(v_{t+1} / v_{t}\right)$ for the generic variable $v_{t}$. Note that in equation (18) we have defined the augmentation rate $\rho$ as

$$
1+\rho \equiv(1+\varepsilon)(1+\delta)(1+n)^{-1} .
$$

In the following paragraphs, we describe the laissez-faire equilibrium and analyze the implications of intergenerational transfers.

Laissez-faire economy. Setting tax-subsidy rates equal to zero, it follows from (15) that the natural capital-resource asset ratio is constant over time

$$
z_{t}=\frac{\alpha(1+\beta)}{\beta(1-\alpha)}=\tilde{z} \text { for all } t .
$$

The laissez-faire economy exhibits the knife-edge property: setting $z_{t+1}=$ $z_{t}=\tilde{z}$ in (18), the net growth rate of output per worker is constant over time, and it can be positive or negative, depending on parameters. With respect to Mourmouras (1993), the presence of technological progress modifies the

${ }^{4}$ Detailed derivations and proofs can be found in the Mathematical Appendix of this paper: see Valente (2006). 
link between resource depletion and sustainability, determining possible conflicts among alternative social objectives. In fact, a necessary and sufficient condition for no depletion in the laissez-faire economy is

$$
\tilde{z} \leq \varepsilon,
$$

whereas:

Proposition 1. A necessary and sufficient condition for sustainability in the laissez-faire economy is

$$
\tilde{z} \leq \rho,
$$

or equivalently

$$
1+\gamma \leq\left(\frac{1-\alpha}{\alpha}\right)\left[\frac{(1+\delta)(1+\varepsilon)}{(1+n)}-1\right]-1
$$

where $\gamma=\beta^{-1}-1$ is the individual pure rate of time preference.

Proof. Under laissez-faire $z_{t+1}=z_{t}=\tilde{z}$, which implies that $U_{t}$ is linear in $\log y_{t}$. Hence, condition (1) is met under laissez-faire only if $\theta^{y} \geq 1$. Substituting $\tilde{z}$ in (18) it follows that $\theta^{y} \geq 1$ requires that (22) be satisfied. Substituting (15) and $\gamma=\beta^{-1}-1$ in (22) yields (23).

Expression (23) is conceptually analogous to the long-run sustainability condition which holds in economies with infinitely lived agents: nondeclining welfare requires that the positive joint effect of technical progress $(\delta)$ and natural regeneration $(\varepsilon)$ not be offset by the impatience to consume $(\gamma) .{ }^{5}$ Whether sustainability conditions are more restrictive than conditions for no depletion depends on the gap between the rates of technological progress and population growth: no depletion per se does not guarantee sustained utility, and different combinations of parameters may determine sustainability, no depletion, both, or neither of the two. The interrelations, and possible conflicts, between alternative social objectives are described in figure 1 . Note that if $\tilde{z}=\varepsilon$ and $\delta=n$, lifetime utility and the resource stock are both constant over time. This special case, represented by point $S$ in figure 1, satisfies most conventional notions of sustainability: utility is nondeclining (standard definition), each generation enjoys the same welfare level (intergenerational equity), and natural capital as such is preserved over time (strong sustainability).

Intergenerational transfers. Proposition 1 suggests that if the economy is unsustainable under laissez-faire, a ceteris paribus reduction in $z_{t}$ due to intergenerational transfers will bring the economy towards the sustainability threshold. Balanced budget policies affect the gap $\left(z_{t}-\tilde{z}\right)$ unambiguously: from (15) and (20)

$$
z_{t}=\tilde{z}\left(1-\tau_{t}\right)\left(1-d_{t}\right)
$$

${ }^{5}$ In the standard capital-resource model, optimal consumption per capita is asymptotically non-decreasing if the social discount rate does not exceed the sum of the rates of technical progress and natural regeneration (Valente, 2005). 


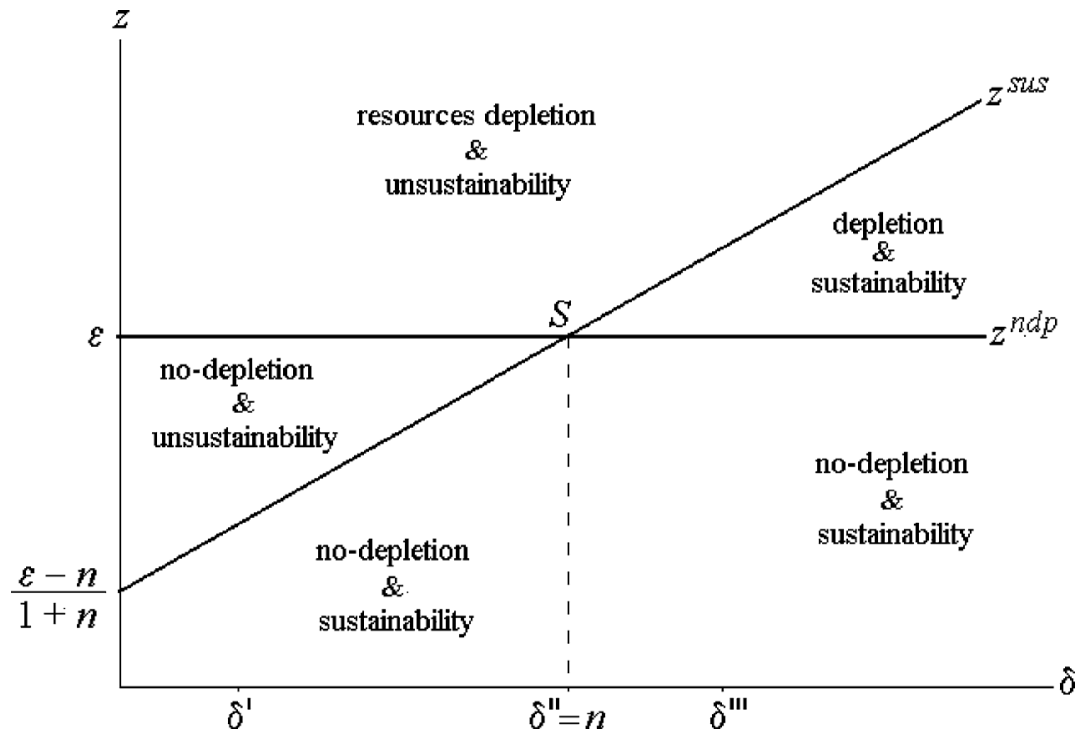

Figure 1. From (21) and (22), the sustainability threshold $z^{\text {sus }}=\rho$ increases with $\delta$, while the no depletion locus $z^{n d p}=\varepsilon$ is horizontal in the $(\delta, z)$ plane. If $\delta<n$, the laissez-faire economy may exhibit no depletion together with unsustainability; if $\delta>n$, the economy may exhibit resource depletion together with sustainability.

Assume that the policymaker aims at achieving a pre-determined level $z^{\prime}$. Substituting (24) in the government budget constraint (11), the target level $z_{t}=z^{\prime}$ is obtained by setting $d_{t}=d^{\prime}$ and $\tau_{t}=\tau^{\prime}$, where

$$
d^{\prime}=\left(\tilde{z}-z^{\prime}\right)(1+\tilde{z})^{-1} \text { and } \tau^{\prime}=\left(\tilde{z}-z^{\prime}\right)\left[\tilde{z}\left(1+z^{\prime}\right)\right]^{-1} .
$$

For example, setting $z^{\prime}=\varepsilon$ in (25) yields tax-subsidy rates that implement zero depletion of the resource stock. By the same reasoning: ${ }^{6}$

Lemma 2. Setting $z^{\prime}=\rho$ in each period implies $U_{t+1}=U_{t}$ for all $t \in[0, \infty)$.

More generally, any fiscal intervention that keeps $z_{t}$ below the laissezfaire level $\tilde{z}$ constitutes a resource-saving policy : lowering the natural capital-resource assets ratio corresponds to lower rates of resource use in production, or equivalently, to a higher degree of preservation. Note that an equivalent resource-saving effect is obtained if the government taxes resource use of firms, as shown by Mourmouras (1993: section 5.1).

\section{Resource-saving transfers and lifetime welfare}

We now compare the welfare effects of laissez-faire and transfers in each period. In this regime-contingent formulation, individual payoffs represent the potential political support for resource-saving measures, as if agents were asked to choose between laissez-faire and intergenerational transfers

${ }^{6}$ All lemmas are proved in Valente (2006). 
during their life. Assuming that each newborn agent takes the history of previous regimes as given, it is shown that resource-saving transfers in both periods of life may yield higher payoffs with respect to laissez-faire if a precise condition regarding parameters is satisfied.

\subsection{Regime-contingent payoffs}

Denote by $\eta_{t}$ the outcome of an unspecified political process, indicating whether laissez-faire or resource-saving transfers are implemented in period $t$

$$
\eta_{t}=\left\{\begin{array}{l}
0 \Leftrightarrow z_{t}=\tilde{z} \quad \text { (laissez-faire) } \\
1 \Leftrightarrow z_{t}=z^{\prime}<\tilde{z} \text { (resource-saving transfers) }
\end{array}\right.
$$

The individual payoff $V_{t}$ of each agent born in $t \geq 0$ depends on the two outcomes realized during his lifetime $\left(\eta_{t}\right.$ and $\left.\eta_{t+1}\right)$ as well as on the whole history of previous outcomes $H_{t}=\left\{\eta_{0}, \eta_{1}, \ldots, \eta_{t-1}\right\}$

$$
V_{t}\left(\eta_{t}, \eta_{t+1}, H_{t}\right)=U_{t}\left[c_{t}\left(\eta_{t}, H_{t}\right), e_{t+1}\left(\eta_{t}, \eta_{t+1}, H_{t}\right)\right]
$$

Since agents cannot modify previous outcomes, $H_{t}$ is taken as given and the individual payoff of an agent born in $T \geq 0$ can be written as (see Valente, 2006)

$$
V_{T}\left(\eta_{T}, \eta_{T+1}\right)=\Omega_{T}+\log \left\{\left(\frac{z_{T}}{1+z_{T}}\right)^{\alpha}\left[\frac{(1+\rho) z_{T+1}}{\left(1+z_{T}\right)\left(1+z_{T+1}\right)}\right]^{\alpha \beta}\right\}
$$

where $\Omega_{T}=\Omega_{T}\left(H_{T}\right)$ depends on previous regimes. We will refer to $V_{T}(0,0)$ and $V_{T}(1,1)$ as payoffs yielded by life-persistent regimes $\left(\eta_{t}=\eta_{t+1}\right)$. Computing the various payoffs on the basis of (28), it follows that

$$
\begin{aligned}
& V_{T}(0,0)>V_{T}(0,1), \\
& V_{T}(1,0)>V_{T}(1,1),
\end{aligned}
$$

for any $z^{\prime}<\tilde{z}$. On the one hand, this result is intuitive: inequalities (29) and (30) imply that if agents could choose $\eta_{T+1}$ taking the previous regime $\eta_{T}$ as given, they would prefer avoiding taxation in the second period of life. On the other hand, (29) and (30) do not rule out situations where selfish agents would prefer persistent transfers to persistent laissez-faire: $V_{T}(1,1)$ and $V_{T}(0,0)$ cannot be ranked a priori, so it is possible to have the interesting case

$$
V_{T}(1,0)>V_{T}(1,1)>V_{T}(0,0)>V_{T}(0,1) .
$$

The explicit condition for obtaining (31) is derived below.

Proposition 3. Individual payoffs are ranked as in (31) if and only if

$$
\left(\alpha \frac{1+\beta}{\beta+\alpha}\right)^{1+\beta}\left(\beta \frac{1-\alpha}{\beta+\alpha}\right)^{\beta}<\left(\frac{z^{\prime}}{1+z^{\prime}}\right)^{1+\beta}\left(1+z^{\prime}\right)^{-\beta} .
$$



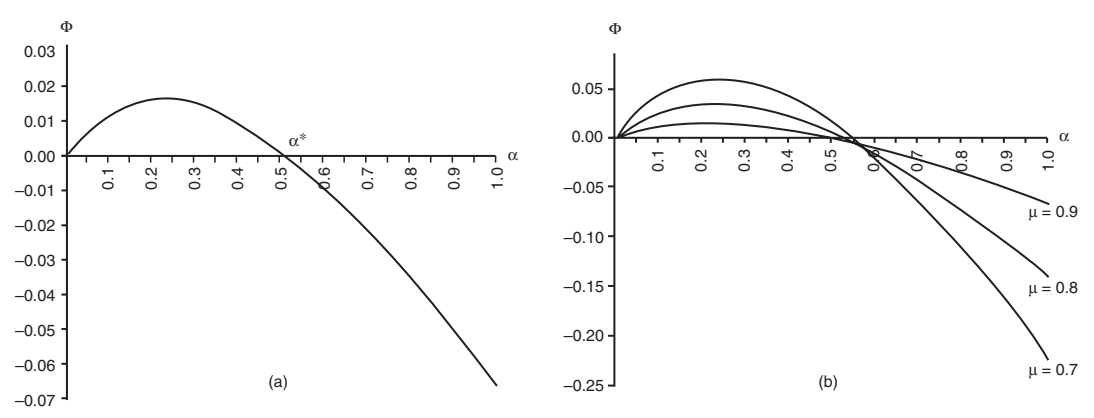

Figure 2. Graph (a): fixing $\beta=0.625$ and $\mu=0.9$, the gap $\Phi=V(0,0)-V(1,1)$ is an inverted- $U$ function of $\alpha$. Condition (32) defines the interval $\left(\alpha^{*}, 1\right)$ over which $V(1,1)>V(0,0)$. Graph $(b)$ : the welfare gap as a parametric function of $\mu=\{0.7,0.8,0.9\}$. The critical threshold increases as $\mu$ declines.

Proof. Substituting $z_{T}$ and $z_{T+1}$ in (28) for the two regimes considered, it follows that $V(0,0)<V(1,1)$ if and only if

$$
\left(\frac{\tilde{z}}{1+\tilde{z}}\right)^{\alpha(1+\beta)}\left(\frac{1}{1+\tilde{z}}\right)^{\alpha \beta}<\left(\frac{z^{\prime}}{1+z^{\prime}}\right)^{\alpha(1+\beta)}\left(\frac{1}{1+z^{\prime}}\right)^{\alpha \beta} .
$$

Substituting $1+\tilde{z}=(\alpha+\beta)[\beta(1-\alpha)]^{-1}$, this inequality reduces to (32). From (29) and (30), if (32) is satisfied the only possible ranking is (31).

Condition (32) is necessary and sufficient to have $V_{T}(1,1)>V_{T}(0,0)$, i.e. private agents strictly prefer persistent transfers to laissez-faire. For a given discount factor $\beta$, inequality (32) defines the set of all possible combinations of $\alpha$ and $z^{\prime}$ implying $V_{T}(1,1)>V_{T}(0,0)$. This set can be characterized by defining the policy index $\mu \equiv z^{\prime} / \tilde{z}$, which is determined by fiscal authorities through the level of tax-subsidy rates: from (24), the policy index equals $\mu=(1-\tau)(1-d)$, and $\mu<1$ indicates a resource-saving policy. Using (28), the welfare gap $\Phi=V(0,0)-V(1,1)$ can be written as

$$
\Phi=\log \left\{\left(\frac{1}{\mu}\right)^{\alpha+\alpha \beta}\left[\frac{\beta(1-\alpha)+\mu \alpha(1+\beta)}{\beta(1-\alpha)+\alpha(1+\beta)}\right]^{\alpha+2 \alpha \beta}\right\},
$$

Fixing $\beta$ and $\mu$, the gap function $\Phi(\alpha)$ has an inverted-U shape: as shown in figure 2(a), there exists a critical value $\alpha^{*}>0$ such that $\Phi\left(\alpha^{*}\right)=0$, with $\Phi$ being negative (positive) when the resource share exceeds (falls short of) this threshold level. ${ }^{7}$ In other words, if the resource share exceeds a critical threshold level, lifetime utility is higher with persistent transfers than under laissez-faire conditions. The economic interpretation of this result is as follows: reducing the rate of resource depletion in $t$ implies higher output growth in $t+1$; if

${ }^{7}$ From (33), it can be shown that $\Phi \leq 0$ requires

$$
\alpha \geq \beta(1+\hat{\mu})[\hat{\mu}-\mu+\beta(1-\mu)]^{-1} \in(0,1),
$$

where $\hat{\mu}=\mu^{(1+\beta) /(1+2 \beta)}>\mu$. I thank an anonymous referee for suggesting this proof. 
resource productivity is sufficiently high, this favorable effect on secondperiod income offsets the negative effect due to taxation. Note that the critical level of the resource share depends on policy targets: as shown in figure $2(b), \alpha^{*}$ is higher the lower is $\mu$. This is because $\mu$ is lower the higher is the level of transfers: if fiscal authorities impose slight deviations from laissez-faire ( $\mu$ close to 1 ), the private cost of transfers is relatively small and condition (32) is likely to be met; conversely, if the policymaker is more inclined towards natural preservation ( $\mu$ close to 0$)$, persistent transfers are more demanding and condition (32) is more restrictive.

From a policymaking perspective, the result that permanent transfers may be welfare improving for newborn generations is relevant. In particular, ranking (31) suggests that, while individual preferences about policy regimes can be in favor of intergenerational transfers, this private desire for resource-saving policies unfolds if generations are credibly pre-committed. This statement is investigated in section 3.3., where the commitment device is represented by lifetime contracts. In a sequential choice setting, instead, unanimous political support without commitment can only be achieved through cooperative voting: in this regard, section 3.4 shows that cooperation can be induced by positive costs of regimeswitching. Before discussing these issues, we complete the analysis of distortionary transfers by comparing first-best and second-best policies for intergenerational equity.

\subsection{First-best and second-best policies}

In order to assess the effects of distortionary transfers on allocative efficiency, a convenient benchmark is to assume that the policy target is to achieve intergenerational equity. ${ }^{8}$ In this case, the first-best allocation is the Rawlsian optimum, which requires two conditions to be satisfied: first, all generations enjoy the same utility level $U^{*}$; second, $U^{*}$ must be the maximum utility level that can be sustained indefinitely. The first condition requires $m_{t} x_{t}$ constant over time

$$
x_{t}^{*}=\left(\frac{1}{1+\delta}\right)^{t} \frac{\rho}{1+\rho} r_{0}, \quad r_{t}^{*}=\left(\frac{1}{1+\delta}\right)^{t} r_{0} .
$$

The depletion path (34) implies a constant output level $y^{*}=[\rho(1+$ $\left.\rho)^{-1} m_{0} r_{0}\right]^{\alpha}$. The second condition requires

$$
c_{t}=c^{*}=(1+\beta)^{-1} y^{*}, \quad e_{t}=e^{*}=\beta(1+n)(1+\beta)^{-1} y^{*} .
$$

Hence, along the first-best path, utility equals

$$
U^{*}=\log \left\{[\beta(1+n)]^{\beta}\left[y^{*}(1+\beta)^{-1}\right]^{1+\beta}\right\}
$$

for all agents born in $t \geq 0$. If the government aims at implementing the Rawlsian optimum, a first-best policy is one that decentralizes the allocation described by (34)-(35). Exactly as in Mourmouras (1993), the first-best policy cannot rely on a lump-sum transfer scheme alone, due to the

\footnotetext{
${ }^{8}$ Mathematical details and proofs for this section are omitted to save space: see Valente (2006).
} 
asymmetric intergenerational distribution of property rights over natural resources. More precisely, achieving the first-best requires expropriating natural capital of the initial old generation: at $t=0$ the whole resource stock is nationalized; old agents at $t=0$ receive a stock of fiat currency that will be transferred to successive generations when acquiring output units; at each $t \geq 0$, the government sells $x_{t}^{*}$ units of resources to firms, and rebates the proceeds to the young generation via lump-sum transfers. This policy is equivalent to a redistribution of property rights across generations operated in each period by fiscal authorities, and implies the same utility level (36) for all agents born in $t \geq 0 .{ }^{9}$

The fact that, under the first-best policy, the initial old generation is expropriated is of particular interest here. In section 3.1, distortionary policies aimed at reducing the rate of resource use also imply a welfare reduction for the initial old generation. In order to compare the two policies, consider a couple of tax-subsidy rates that implement a constant-utility path. As shown in Lemma 2, this means that authorities set $z^{\prime}=\rho$ in each period, and obtain (34). With $x_{t}=x_{t}^{*}$, output equals $y_{t}=y^{*}$ in each period. However, with respect to the Rawlsian optimum, consumption is lower in the first period and higher in the second

$$
\begin{aligned}
& c_{t}=c^{* *}=(1-\alpha)(1+\beta)^{-1} y^{*}<c^{*}, \\
& e_{t}=e^{* *}=(\alpha+\beta)(1+n)(1+\beta)^{-1} y^{*}>e^{*} .
\end{aligned}
$$

From (36) and (37)-(38), lifetime welfare under this policy, $U^{* *}$, is below the first-best

$$
U^{*}-U^{* *}=\log \left\{(1-\alpha)^{-1}[\beta /(\alpha+\beta)]^{\beta}\right\}>0 .
$$

The central term in (39) is the efficiency loss in utility terms implied by the second-best policy. However, the two policies cannot be Pareto ranked: from (38), the utility level of the first old generation is higher under the secondbest policy. In other words, if agents face an exclusive choice between the two policies, the young prefer the first-best scheme with nationalization of the resource stock, whereas the old are better off under distortionary transfers.

\subsection{Lifetime contracts}

It follows from Proposition 3 that, when (32) is satisfied, if agents are asked at birth to sign a lifetime contract requiring them to choose between persistent transfers and persistent laissez-faire, every agent born in $t \geq 0$ chooses resource-saving transfers. With respect to this result, three main points should be emphasized. First, lifetime contracts embody a notion of credible commitment: under ranking (31), agents prefer resource-saving transfers as long as no regime switch is allowed during the life-cycle. Second, agents

${ }^{9}$ The difference with respect to Mourmouras (1993) is given by the presence of technical progress, which implies that (i) natural capital per capita $x_{t}^{*}$ declines over time (instead of being constant); (ii) the Rawlsian optimum is technically feasible even with exhaustible resources $(\varepsilon=0)$; (iii) the resource stock $R_{t}$ can be either declining, constant, or increasing, depending on the gap $(\delta-n)$. 
would not enforce such contracts by themselves because resource owners at $t=0$ receive no compensation: this is the 'first-father problem' discussed below. Third, whether a sustainable path would be supported depends on the whole set of parameters. As shown in figure 2(b), the technological condition is more restrictive the lower is $\mu$. This implies that the threshold $\alpha^{*}$ is very high when the 'sustainability gap' $(\tilde{z}-\rho)$ is huge, whereas conditions for an agreement on sustainability are less restrictive when $\tilde{z}$ is relatively close to $\rho$. However, section 4 shows that when other financial assets exist in the economy, the critical threshold for the resource share is reduced, and its sensitivity to policy targets becomes less critical in this regard.

When considering an infinite time horizon, the individual first-best payoff cannot be assigned to each generation, since implementing $V_{t}(1,0)$ in each $t$ is impossible. From a social-planning perspective, the relevant inequality in (31) is thus the central one, $V(1,1)>V(0,0)$, which refers to life-persistent regimes. This in turn suggests studying the welfare time paths implied by the sequences $\left\{\tau_{t}=0, d_{t}=0\right\}_{t=0}^{\infty}$ and $\left\{\tau_{t}=\tau^{\prime}, d_{t}=d^{\prime}\right\}_{t=0}^{\infty}$. We refer to these sequences as permanent laissez-faire and permanent transfers, respectively. Since the initial resource stock is owned by the old at time zero, a typical 'first-father problem' arises: if transfers are voted into existence at $t=0$, all successive generations gain from permanent transfers, but initial subsidies are financed at the expense of the first old generation. This generation bears the burden of the new regime without gaining from it, and welfare improvements thus pertain to newborn agents. In this regard, we can make two remarks. First, the initial welfare loss for resource owners implies that the two sequences, permanent laissez-faire and permanent transfers, cannot be Pareto ranked. Second, due to the first-father problem, enacting permanent transfers involves a paternalistic action at time zero, as no generation would selfishly make the initial gift. In this respect, resourcesaving policies recall the logic of Gale-type intergenerational transfers: considering a two-generations pure exchange economy, Gale (1973) showed that the first generation can raise future welfare by renouncing part of its claim over the endowment to the benefit of the second generation, which in turn transmits a claim to its successor, and so on. In our setting, transfers work in a similar way: the initial tax $\tau_{0} p_{0} X_{0}$ amounts to the share of claims over natural capital not received by the first owner, and subsidies to the newborn bring the associated credit forward in time. The main differences with respect to Gale (1973) are that transfers are distortionary, require commitment, and yield welfare gains only if the critical condition is satisfied. Nonetheless, Gale's conclusion can be readapted to the present context as follows: resource-saving transfers begin after the economy:

has been running along for some time in the [no-transfers] equilibrium, but at time $t=0$ some of the old people realize that if they are willing to give up ever so little of their second-period consumption, the economy in the future will move up toward [higher welfare for future generations]. (...) If this altruistic scenario sounds too unrealistic, one can instead imagine a central authority which levies an income tax on the old people 
in period zero and then sells this income back to the young. (ibid., p. 29)

Alternatively, we can imagine a privatization scenario where natural resources previously owned by the State are sold at a lower-than-efficiency price to young generations in period zero, and permanent transfers are then implemented. ${ }^{10}$

\subsection{Sequential voting}

With lifetime contracts, resource-saving policies are supported by successive generations because agents are credibly committed to pay second-period taxes. An alternative interpretation of Proposition 3 derives from assuming a sequential process generating political decisions. Suppose that fiscal authorities act in a representative democracy, and implement the regime voted by the citizens in each period: all individuals alive in period $t$ face a discrete choice between laissez-faire $\left(z_{t}=\tilde{z}\right)$, and a certain amount of transfers corresponding to the policy proposed by fiscal authorities $\left(z_{t}=z^{\prime}<\tilde{z}\right)$. For a given voting rule, the sequence of depletion rates is determined by the outcomes of an indefinitely repeated game. Similar games are used in the recent literature on social security systems and political economy (Cooley and Soares, 1998; Boldrin and Rustichini, 2000; Azariadis and Galasso, 2002). These contributions study whether pay-asyou-go social security systems may result from political equilibria when private agents choose to create, maintain, or dismantle intergenerational transfers. A similar reasoning will be followed here, the main difference being that the direction of transfers implied by pension financing (young-toold) is opposite to that implied by resource-saving policies (old-to-young). In particular, the different configuration of payoffs in the present model implies the following:

Lemma 4. If (32) holds, young agents support resource-saving transfers in any subgame perfect equilibrium sequence.

The intuition for this result follows immediately from (31): laissez-faire choices in the first period are ruled out by the fact that young agents prefer resource-saving transfers irrespective of second-period outcomes. The difference with respect to social-security games is twofold. On the one hand, Lemma 4 departs from the result, established by Boldrin and Rustichini (2000: 51), that laissez-faire outcomes can be part of an equilibrium sequence in pension games (see Valente, 2006). On the other hand, Lemma 4 implies that in a growing economy $(n>0)$, simple-majority rules suffice to obtain permanent transfers as a political equilibrium $\left(\eta_{t}=1\right.$ in each $\left.t \geq 0\right) .{ }^{11}$ This is

${ }^{10}$ In this case, the initial selling price (determined by the government) is equivalent to a proportional subsidy to the young at time zero: under a balanced budget, the efficiency loss for the public owner would fall again on the first old generation in the form of reduced transfers.

${ }^{11}$ As in Azariadis and Galasso (2002), consider a simple-majority rule operating among homogeneous agents within each cohort: if the net rate of population growth is positive (negative), the majority of citizens is constituted by young 
in contrast to the standard result that the open-loop equilibrium in pension games features permanent laissez-faire (Hammond, 1975; Sjoblom, 1985; Azariadis and Galasso, 2002). ${ }^{12}$

In general, the configuration of payoffs in (31) implies that coexisting generations never cooperate. To see this, consider a qualified-majority rulethat is, if both cohorts vote for a given regime in $t$, this regime will be established; otherwise, the previous regime is maintained $\left(\eta_{t}=\eta_{t-1}\right) \cdot{ }^{13} \mathrm{In}$ this case, any regime established at $t=0$ becomes a self-sustained regime irrespective of the population growth rate:

Lemma 5. Under qualified-majority voting, if (32) holds, then $\eta_{t}=\eta_{0}$ in each $t>0$.

It follows from the above discussion that intergenerational compromise is lacking as long as old agents have no incentives to cooperate with the currently young. In this respect, cooperative voting may be induced by a positive cost of regime-switching. More precisely, a transfer regime already in place is sustained indefinitely with unanimous consensus, provided that a regime switch involves relevant costs for all agents. The presence of regime-switching costs can be interpreted in two ways: it may reflect an exogenous (e.g. administrative) cost of reforms, or represent an 'over-rule tax'. In either case, the analysis of payoffs is identical: denoting by $\epsilon_{t}\left(\eta_{t-1}\right)$ the welfare cost of a regime switch in period $t$, and by $\bar{V}_{t}$ individual payoffs, the following result holds:

Lemma 6. Suppose $\eta_{t-1}=1$ at $t>0$. If

$$
\epsilon_{t}(1)>\Phi
$$

and

$$
\epsilon_{t+1}(1)>\log \left(\frac{1+\mu \tilde{z}}{\mu+\mu \tilde{z}}\right)^{\alpha},
$$

agents born in $t$ support transfers in both periods of life. If (40)-(41) hold at all $t \geq 0$, setting $\eta_{0}=1$ implies unanimous support for transfers at all future dates.

The reasoning behind Lemma 6 is that when the loss implied by a regime switch is sufficiently high, permanent transfers become the firstbest individual payoff: in fact, satisfying condition (41) implies $\bar{V}_{t}(1,1)>$ $\bar{V}_{t}(1,0)$, so that agents will vote for resource-saving transfers not only

(old) agents. Sincere voting implies that the political outcome $\eta_{t}$ coincides with the action of the young when $n>0$. Hence, if $n>0$ and condition (32) holds, resource-saving transfers are voted into existence from $t=0$ onward.

12 The reason for this result is that, in pension games, young agents - the majority of citizens when $n>0$ - do not finance current pensions in the absence of commitment devices that bind the next generation (see Azariadis and Galasso, 2002: 260).

${ }^{13}$ This voting mechanism is used in many countries, e.g. while voting to modify constitutional norms, in order to guarantee that specific norms are also accepted by at least a fraction of parties that usually oppose the 'standard majority'. 
when young (in $t$ ), but also when old (in $t+1$ ). With respect to this result, we can make three remarks. First, Lemma 6 does not assume that the usual critical condition be satisfied, since condition (40) is sufficient to have $\bar{V}_{t}(1,1)>\bar{V}_{t}(0,0)$ and is less restrictive than (32) ${ }^{14}$ Second, the cost of regime-switching is assumed to be time-varying and regimecontingent for the sake of generality: if it is interpreted as an exogenous administrative cost, further assumptions yield symmetry in states (i.e. going from laissez-faire to transfers is as costly as doing the opposite reform) and stationary costs, in which case conditions (40)-(41) can be expressed in terms of exogenous parameters. Third, the cost of regime-switching can be alternatively interpreted as an over-rule tax, which essentially constitutes a commitment technology for young generations.

More generally, in the vast majority of sequential games, a paternalistic action at $t=0$ is required to induce permanent resource-saving transfers. It should be stressed, however, that this variant of the 'first-father problem' does not originate in the distortionary character of transfers: recalling the results of section 3.2, the amount of resources subtracted from the initial old is even higher under a first-best policy. If the first father faced an exclusive choice between first- and second-best policies, he would vote for distortionary transfers in order to avoid expropriation.

\section{Capital, monopoly rents and $R \& D$ activity}

The basic model is now extended to include other assets, in addition to natural capital, which represent individual wealth. In this section, we present critical conditions that are conceptually analogous to (32), in the presence of man-made capital, monopolistic sectors, and R\&D firms developing innovations. For simplicity, we rule out population growth $(n=0)$ and normalize total labor supply to unity $\left(N_{t}=1\right)$. Exogenous progress is also ruled out $(\delta=0)$, since we will reintroduce endogenous technical change under a slightly different production function (section 4.3). Mathematical derivations and details about the models considered in this section can be found in Valente (2006).

\subsection{Man-made capital}

With $\delta=0$, the model with man-made capital is essentially that in Mourmouras (1993: section 6), with the addition of distortionary transfers. Aggregate output is now given by $Y=X^{\alpha_{1}} N^{\alpha_{2}} K^{\alpha_{3}}$ with constant returns to scale $\left(\alpha_{1}+\alpha_{2}+\alpha_{3}=1\right)$, implying

$$
y_{t}=x_{t}^{\alpha_{1}} k_{t}^{\alpha_{3}}
$$

where $k \equiv K / N$ is individual capital. Agents may allocate savings in assets representing either natural or man-made capital. Tax-subsidy rates $(d, \tau)$ are constant and set compatibly with a balanced budget in each period, and the aggregate constraint of the economy is $k_{t+1}=y_{t}-c_{t}-e_{t}$. The equilibrium

${ }^{14}$ In fact, the critical condition (32) implies $\Phi<0$, but ( 40) can be satisfied even if $\Phi>0$. 
is characterized by

$$
\begin{aligned}
c_{t} & =(1+\beta)^{-1} w_{t}, \\
i_{t+1}^{k} & =\frac{q_{t+1}}{q_{t}}\left(\frac{1+\varepsilon}{1-d}\right)=\frac{e_{t+1}}{\beta c_{t}},
\end{aligned}
$$

where $i_{t+1}^{k}$ is the interest factor, equal to the gross marginal rent from manmade capital. The central term in (44) is due to the Hotelling rule - the net rate of growth in resource prices must equal the interest rate - whereas the last term derives from the standard Euler condition for consumption allocation. The equilibrium propensity to invest is now affected by the capital share $\alpha_{3}$, which in turn modifies the depletion index $z_{t}=x_{t} / a_{t}$. With constant tax-subsidy rates, $z_{t}$ is constant and given by

$$
\alpha_{3}\left(\frac{1-d}{1+z}\right)+\frac{\alpha_{1}}{z}(1-d)(1-\tau)-\frac{\alpha_{2} \beta}{1+\beta}=0 .
$$

Expression (45) reduces to a quadratic equation in $z$ with only one admissible (positive) root. With $d=\tau=0$, the same procedure gives the laissez-faire value $\tilde{z}$. Equilibrium dynamics thus feature a constant rate of depletion of the resource stock, $\theta^{x}=(1+\varepsilon)(1+z)^{-1}$, whereas output and man-made capital display transitional dynamics. However, man-made capital and output converge to the same (constant) growth rate in the long run, which equals ${ }^{15}$

$$
\lim _{t \rightarrow \infty} \theta_{t}^{y}=[(1+\varepsilon) /(1+z)]^{\frac{\alpha_{1}}{1-\alpha_{3}}} .
$$

Expression (46) shows that a reduction in $z$ increases the long-term growth rate more intensively the higher the capital share $\alpha_{3}$. This suggests that the presence of capital improves the effectiveness of resource-saving policies in sustaining welfare over time. To address this point, consider a policy target $\mu=z^{\prime} / \tilde{z}<1$. As shown in Valente (2006), the critical condition for obtaining $\Phi<0$ is independent of the presence of transitional dynamics, ${ }^{16}$ and reads

$$
\left(\frac{1+\mu \tilde{z}}{\mu+\mu \tilde{z}}\right)^{\alpha_{1}+\alpha_{1} \beta\left(1+\alpha_{3}\right)}\left(\frac{1+\mu \tilde{z}}{1+\tilde{z}}\right)^{\alpha_{1} \beta}<1
$$

in each period. With respect to the basic model of section 3.1, a slight complication is that $\tilde{z}$ is not linear in $\alpha_{1}$, and the critical condition for the resource share must be obtained numerically. Results differ substantially from the predictions of the basic model: in the model of section 3.1,

${ }^{15}$ Since $\lim _{t \rightarrow \infty} \theta_{t}^{y}=\lim _{t \rightarrow \infty} \theta_{t}^{k}$, technology (42) implies $\theta_{t}^{y}=\left(\theta_{t}^{x}\right)^{\alpha_{1}}\left(\theta_{t}^{y}\right)^{\alpha_{3}}$ as $t \rightarrow \infty$. Substituting $\theta_{t}^{x}=(1+\varepsilon)(1+z)^{-1}$ in this expression we obtain (46).

${ }^{16}$ Condition (47) is obtained by direct substitution of equilibrium relations in the utility function, without assuming steady-state growth rates in man-made capital and output (see Valente, 2006). Since the critical condition depends on the natural capital-resource asset ratio, having a constant $z$ in any policy regime implies a time-invariant inequality, which determines the sign of the welfare gap $\Phi$ in any period. 
condition (32) is usually met for values of the resource share exceeding 0.5 - a rather high value, from an empirical perspective. In the present model, instead, capital productivity affects condition (47) through $\alpha_{3}$, and the critical threshold is far below 0.5 under reasonable parameters. In the example reported in table 1 , we fix $\alpha_{2}=0.4$ and let $\alpha_{1}$ and $\alpha_{3}$ vary, assuming $\beta=0.625$. The critical resource share is $\alpha_{1}^{*} \simeq 0.17$ with 'light

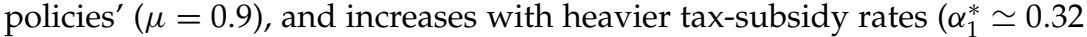
with $\mu=0.7)$. The interpretation of this result is that the presence of capital enhances the mechanism via which first-period subsidies may compensate, in terms of utility, the negative effects of second-period taxation: the reduction in resource depletion in $t$ increases output levels in $t+1$, with a positive level effect on private returns from natural and man-made capital. The next section shows that this conclusion is robust to alternative assumptions regarding the nature of financial assets held by private agents.

\subsection{Monopoly rents}

In this section we substitute man-made capital with assets representing claims over future monopoly rents. This framework will be extended in section 4.3 to include endogenous technical change generated by R\&D activity. The supply side of the economy now consists of producers of final output $(Y)$ and firms producing intermediate products $(B)$. Final output is obtained by means of natural capital, labor, and a number $g$ (assumed exogenous, for the moment) of intermediate goods' varieties. Denoting by $B_{(j)}$ the quantity of the $j$ th intermediate output equals

$$
Y_{t}=X_{t}^{\nu_{1}} N^{\nu_{2}} \sum_{j=1}^{g} B_{(j), t}^{\nu_{3}},
$$

where $v_{1}+v_{2}+v_{3}=1$. Each variety is produced by a monopolist with unit production cost. Denoting by $p_{(j)}^{b}$ the price of intermediates, each monopolist maximizes profits $\bar{\pi}_{(j)}=B_{(j)} p_{(j)}^{b}-B_{(j)}$ taking the demand schedule of final producers as given. First-order conditions imply $p_{(j)}^{b}=v_{3}^{-1}$ in each period, so that prices and quantities of intermediates are invariant across varieties

$$
B_{t}=B_{(j), t}=\left(v_{3}^{2} X_{t}^{v_{1}} N^{v_{2}}\right)^{\frac{1}{1-v_{3}}} .
$$

Monopolistic firms are owned by the currently old generation. Old agents in period $t$ thus receive the per capita profit rate

$$
g \pi_{t}=\left(g / v_{3}\right)\left(1-v_{3}\right) b_{t},
$$

where $\pi_{t}=\bar{\pi}_{t} / N$ and $b_{t} \equiv B_{t} / N$. Note that (49) and (50) imply that output grows at the same rate as intermediate quantities and monopoly profits

$$
y_{t}=v_{3}^{-2} g b_{t}, \quad \theta_{t}^{y}=\theta_{t}^{b}=\theta_{t}^{\pi} .
$$

Each firm producing a variety holds the relevant patent, and old agents control the exclusive right to produce existing intermediate goods. Since individuals die after the second period, young agents buy patents in period $t$ in order to run monopolistic firms in $t+1$. This is equivalent 
to assuming that the young invest in single-period obligations of a consolidated intermediate sector, representing claims over future monopoly rents. Denote by $v_{(j), t}$ the forward patent value, i.e. the value in period $t$ of a patent exploitable to produce the $j$ th variety in period $t+1$. Since profits are invariant across varieties, $v_{(j), t}=v_{t}$ for any $j \in[1, g]$. The total value of patents in the intermediate sector is $F_{t} \equiv g v_{t}$, and individual budget constraints read

$$
\begin{aligned}
c_{t} & =w_{t}-q_{t} a_{t}(1-d)-f_{t}, \\
e_{t+1} & =p_{t+1} x_{t+1}(1-\tau)+q_{t+1} a_{t+1}+g \pi_{t+1}+f_{t+1},
\end{aligned}
$$

where $f \equiv F / N$. The implicit interest factor is now defined as the gross return on assets

$$
i_{t+1}^{f}=\left(\pi_{t+1}+f_{t+1}\right) / f_{t},
$$

and the aggregate constraint of the economy is

$$
y_{t}=c_{t}+e_{t}+g b_{t} \text {. }
$$

Optimality conditions for consumers are the same as in the model with capital - i.e. (43) and (44), with $i_{t+1}^{f}$ replacing $i_{t+1}^{k}$ in (44). The natural capital-resource asset ratio is constant in equilibrium, and equals

$$
z=(1-d)\left[\left(1-v_{3}^{2}\right)(1+\beta)-v_{2}\right]\left(v_{2} \beta\right)^{-1}-1 .
$$

A constant propensity to invest in resources implies constant rates of resource use and output growth. In particular, since $\theta_{t}^{y}=\theta_{t}^{b}$, we have

$$
\theta_{t}^{y}=\left(\theta_{t}^{x}\right)^{\nu_{1}}\left(\theta_{t}^{b}\right)^{\nu_{3}}=\left(\theta_{t}^{x}\right)^{\frac{\nu_{1}}{1-\nu_{3}}}=[(1+\varepsilon) /(1+z)]^{\frac{\nu_{1}}{1-\nu_{3}}} .
$$

Hence, similarly to the model with man-made capital, the presence of intermediates amplifies the growth effects induced by resource-saving policies: transfers increase $\theta^{y}$ by reducing $z$, and the exponent in (57) is increasing in the intermediates share $v_{3}$. The dynamic interaction between resource use and investment in intermediate firms is as follows. The rate of depletion $\theta^{x}$ determines output growth $\theta^{y}$, which is in turn the rate at which monopoly rents develop over time - see (51). Hence, reducing the rate of resource use sustains not only output, but also the profitability of monopolistic firms that represent investment opportunities for young agents. We thus expect a positive influence of $v_{3}$ on the critical condition for $\Phi<0$. The welfare gap $V(0,0)-V(1,1)$ now reads

$$
\Phi=\log \left\{\left(\frac{1}{\mu}\right)^{\frac{v_{1}(1+\beta)}{1-\nu_{3}}}\left(\frac{1+\mu \tilde{z}}{1+\tilde{z}}\right)^{\frac{\nu_{1}(1+2 \beta)}{1-\nu_{3}}}\right\},
$$

where $\tilde{z}$ is given by setting $d=0$ in (56). Looking at table 1 , numerical substitutions suggest that monopoly rents imply $\Phi<0$ for a wide range of parameters: considering different policy targets $(\mu)$ and comparable values of input shares, the critical threshold with monopoly rents equals $v_{1}^{*} \simeq 0.17$ with $\mu=0.9$, and falls short of that obtained with man-made capital under stricter policy targets $\left(v_{1}^{*} \simeq 0.27\right.$ with $\left.\mu=0.7\right)$. 


\subsection{RED activity}

The previous model is now extended to include a third sector which develops innovations: R\&D firms invent new varieties of intermediates, thereby increasing the number of monopolistic firms operating in the economy. We thus obtain a variant of the expanding-varieties model (see Barro and Sala-i-Martin, 2004), which includes overlapping generations and resource extraction. Aggregate output equals

$$
Y_{t}=X_{t}^{v_{1}} N^{v_{2}} \sum_{j=1}^{g_{t}} B_{(j), t^{\prime}}^{\nu_{3}}
$$

where the number of intermediate varieties, $g_{t}$, is now endogenous and generally time-varying. The behavior of monopolistic firms is as before, with profit-maximizing conditions implying $p_{t}^{b}=1 / \nu_{3}$ and $B_{t}=B_{(j), t}$ given by (49). From (59) and (49), equilibrium output per capita is

$$
y_{t}=g_{t} x_{t}^{\nu_{1}} b_{t}^{\nu_{3}}=v_{3}^{-2} g_{t} b_{t}
$$

and equilibrium dynamics imply

$$
\theta_{t+1}^{y}=\theta_{t+1}^{g} \theta_{t+1}^{b}, \quad \theta_{t+1}^{b}=\left(\theta_{t+1}^{x}\right)^{\frac{v_{1}}{1-\nu_{3}}} .
$$

R\&D firms operating in period $t$ invent new varieties that monopolistic firms will exploit at $t+1$. In order to develop $\left(g_{t+1}-g_{t}\right)$ new varieties, the R\&D sector consumes $\bar{h}_{t}$ units of output, and the innovation technology is

$$
g_{t+1}-g_{t}=\xi_{t} \bar{h}_{t},
$$

where $\xi_{t}$, the marginal productivity of R\&D expenditure, is affected by aggregate spillovers generating endogenous growth. In the R\&D literature, spillovers are typically formalized as knowledge-stock externalities, implying that current R\&D activity is more productive the better the stateof-the-art at the aggregate level. In the present model, a convenient index for the state of technology is given by the ratio between the number of existing varieties and current output levels. Assuming a positive relation between $\xi_{t}$ and the state of technology, the aggregate productivity of the R\&D sector increases with the economy-wide rate of R\&D investment:

$$
\xi_{t}=\psi\left(g_{t} / y_{t}\right), \quad \theta_{t+1}^{g}=1+\psi h_{t}^{m},
$$

where $\psi>0$ is a proportionality factor, and $h_{t}^{m} \equiv \bar{h}_{t} / y_{t}$ is the rate of R\&D investment determining, by (62), the rate of expansion in intermediates' varieties. Since profits are invariant across varieties, the value of each new blueprint equals the forward value of a patent $v_{t}$, and equilibrium in the $R \& D$ sector requires ${ }^{17}$

$$
v_{t}=1 / \xi_{t}
$$

${ }^{17}$ Condition (64) maximizes profits $v_{t}\left(g_{t+1}-g_{t}\right)-\bar{h}_{t}$ and implies zero extra profits in the R\&D sector. The same condition is equivalently obtained assuming free entry in the R\&D business for an indefinite number of firms, as in Barro and Sala-i-Martin (2004: Chapter 6). 
From the households' point of view, R\&D firms represent an additional asset: R\&D investment in period $t$ allows young agents to run $\left(g_{t+1}-g_{t}\right)$ new monopolistic firms in the subsequent period, obtaining higher secondperiod income through (i) additional monopoly profits from intermediates' production, and (ii) additional patent sales to newborn generations in $t+1$. This mechanism is summarized by the individual constraints

$$
\begin{aligned}
c_{t} & =w_{t}-q_{t} a_{t}(1-d)-f_{t}-h_{t}, \\
e_{t+1} & =p_{t+1} x_{t+1}(1-\tau)+q_{t+1} a_{t+1}+g_{t+1} \pi_{t+1}+f_{t+1},
\end{aligned}
$$

where $f_{t}=g_{t} v_{t}$ as before, and $h_{t}$ is R\&D investment per capita which equals agents' expenditure to obtain patents for new intermediates. From (64), in aggregate we have

$$
h_{t}=\bar{h}_{t}=\left(1 / \xi_{t}\right)\left(g_{t+1}-g_{t}\right)
$$

the implicit interest factor is ${ }^{18}$

$$
i_{t+1}^{h}=\frac{g_{t}\left(\pi_{t+1}+v_{t+1}\right)}{f_{t}}=\frac{\left(g_{t+1}-g_{t}\right)\left(\pi_{t+1}+v_{t+1}\right)}{h_{t}},
$$

and the aggregate constraint now reads

$$
y_{t}=c_{t}+e_{t}+g_{t} b_{t}+h_{t} .
$$

Expression (69) shows that output can be allocated to consumption, production of intermediates, or R\&D investment in each period. Optimality conditions for consumers are again represented by (43) and (44), with $i_{t+1}^{h}$ replacing the interest factor in (44). The equilibrium propensity to invest in resources is constant, and the depletion index $z$ is recursively determined by the system

$$
\begin{aligned}
z & =(1-d)\left[1+\psi v_{3}\left(1-v_{3}\right)\right]\left[1+\psi h^{m}\right]^{-1}-1, \\
h^{m} & =v_{2} \beta(1+\beta)^{-1}-\psi^{-1}-v_{1}(1-d)(1-\tau) z^{-1},
\end{aligned}
$$

which can be solved as a quadratic equation in $z$ with a unique positive root. From (71), the marginal propensity to invest in $R \& D, h^{m}$, is constant as well and the equilibrium features balanced growth: output per capita grows at the constant rate $\mathrm{e}^{19}$

$$
\theta^{y}=\theta^{g}\left(\theta^{x}\right)^{\frac{\nu_{1}}{1-v_{3}}}=\left(1+\psi h^{m}\right)[(1+\varepsilon) /(1+z)]^{\frac{\nu_{1}}{1-v_{3}}} .
$$

${ }^{18}$ Non-resource income in (66) can be decomposed as the sum of (i) current profits and patent sales of the $g_{t}$ firms that already existed in $t$, and (ii) the gross return to R\&D investment - i.e. profits plus patent sales generated by new blueprints. Condition (68) states that the two returns must coincide in equilibrium: indeed, substituting either (67) or $f_{t}=g_{t} v_{t}$ in (68) gives the standard no-arbitrage condition $v_{t} i_{t+1}=\pi_{t+1}+v_{t+1}$.

${ }^{19}$ Rewriting the innovation frontier as $\theta_{t+1}^{g}=1+\psi h^{m}$ and substituting in (61), we obtain (72). 
Since consumption is proportional to output levels, the necessary and sufficient condition for non-declining welfare is

$$
\left(1+\psi h^{m}\right)[(1+\varepsilon) /(1+z)]^{\frac{\nu_{1}}{1-\nu_{3}}} \geq 1,
$$

which confirms that prospects for sustainability are improved by endogenous technical change - here represented by the rate of expansion in intermediate varieties $\left(1+\psi h^{m}\right)$. The effect of intergenerational transfers on the growth rate is twofold. On the one hand, positive tax-subsidy rates reduce the depletion index $z$, implying the usual mechanism: from (72), a reduction in $z$ directly increases the output growth rate $\theta^{y}$, and this effect is stronger the higher are the shares of resources $\left(v_{1}\right)$ and intermediates $\left(v_{3}\right)$ in production. On the other hand, taxes and subsidies also affect the marginal propensity to invest in $\mathrm{R} \& \mathrm{D}$, and thereby the rate of expansion in intermediate varieties $\left(1+\psi h^{m}\right)$. This second effect is generally ambiguous, but rather unlikely to imply a reduction of output growth following a decrease in the resource depletion rate. ${ }^{20}$

The critical condition for $\Phi<0$ is

$$
\left(\frac{1}{\mu}\right)\left(\frac{1+\mu \tilde{z}}{1+\tilde{z}}\right)^{\frac{1+2 \beta}{1+\beta}}>1,
$$

with numerical results reported in table 1 . For the different policy targets considered, the critical levels of the resource share in the R\&D model occupy intermediate positions if compared with previous models: with R\&D activity, the critical threshold $v_{1}^{*}$ is slightly higher than that obtained with monopoly rents, but may be lower than that obtained in the model with man-made capital with strict policy targets (cf. table 1 with $\mu=0.7$ ). Notice, however, that a sustainability-targeted policy is more politically feasible with R\&D activity: the reason is that sustainability conditions differ between the present model and that with monopoly rents - see (57) and (72) and the growth rate in the economy with R\&D is generally higher. Hence, achieving sustainability in the R\&D economy involves a smaller deviation from laissez-faire (that is, a higher $\mu$ ) with respect to the economy with monopoly rents, which grows less and must fill a bigger sustainability gap (that is, requires a lower $\mu$ ). As a consequence, the critical threshold becomes less restrictive for the economy with R\&D firms. ${ }^{21}$

${ }^{20}$ The effect of a variation in tax-subsidy rates on $h^{m}$ is generally ambiguous since a variation in $d$ and $\tau$ modifies both the numerator and denominator in the last term in (71). However, an interior equilibrium with positive $R \& D$ activity requires $\psi>1$ (see Valente, 2006) and this implies that possible reductions in $h^{m}$ would not reduce the rate of expansion $1+\psi h^{m}$ substantially. The net effect of a reduction in $z$ on output growth thus remains largely determined by the usual mechanism induced by resource preservation.

${ }^{21}$ For example, set $v_{1}=0.25, v_{3}=0.35$, and suppose that the $R \& D$ economy requires a reduction of the depletion index corresponding to $\mu=0.9$. Recalling (57) and (72), the R\&D economy can be safely assumed to be growing faster than a no-R\&D economy with monopoly rents. The latter economy thus requires higher levels of tax-subsidy rates to achieve sustainability, corresponding to (e.g.) $\mu=0.7$. Under these parameters $\left(v_{1}=0.25, v_{3}=0.35\right)$, table 1 shows that the sustainability policy would be politically supported in the R\&D economy $\left(\Phi^{R}=-0.0012\right.$ with $\left.\mu=0.9\right)$, 
Table 1. The welfare gap $\Phi$ under different policy targets in the three variants of the model, with $\beta=0.625:$ monopoly rents ( $\left.\Phi^{M}\right)$, RED firms $\left(\Phi^{R}\right)$, and man-made capital $\left(\Phi^{K}\right.$ : in this case, input shares read $\left.\alpha_{1}, \alpha_{2}, \alpha_{3}\right)$. The welfare gap becomes negative when the resource share (first column) reaches a critical threshold

\begin{tabular}{|c|c|c|c|c|c|c|c|c|c|c|c|}
\hline \multicolumn{3}{|c|}{ Input shares } & \multicolumn{3}{|c|}{$\mu=0.9$} & \multicolumn{3}{|c|}{$\mu=0.8$} & \multicolumn{3}{|c|}{$\mu=0.7$} \\
\hline$v_{1}$ & $v_{2}$ & $v_{3}$ & $\Phi^{M}$ & $\Phi^{R}$ & $\Phi^{K}$ & $\Phi^{M}$ & $\Phi^{R}$ & $\Phi^{K}$ & $\Phi^{M}$ & $\Phi^{R}$ & $\Phi^{K}$ \\
\hline 0.15 & 0.40 & 0.45 & 0.0007 & 0.0066 & 0.0001 & 0.0033 & 0.0180 & 0.0010 & 0.0085 & 0.0363 & 0.0034 \\
\hline 0.20 & 0.40 & 0.40 & -0.0007 & 0.0021 & -0.0004 & 0.0006 & 0.008 . & 0.0004 & 0.0046 & 0.0204 & 0.0030 \\
\hline 0.25 & 0.40 & 0.35 & -0.0022 & -0.0012 & -0.0010 & -0.0025 & 0.0011 & -0.0006 & 0.0002 & 0.0087 & 0.0019 \\
\hline 0.30 & 0.40 & 0.30 & -0.0037 & -0.0037 & -0.0018 & -0.0055 & -0.0043 & -0.0020 & -0.0042 & -0.0003 & 0.0017 \\
\hline 0.35 & 0.40 & 0.25 & -0.0051 & -0.0056 & -0.0027 & -0.0082 & -0.0086 & -0.0037 & -0.0084 & -0.0073 & -0.0021 \\
\hline 0.40 & 0.40 & 0.20 & -0.0063 & -0.0072 & -0.0037 & -0.0107 & -0.1190 & -0.0057 & -0.0121 & -0.0127 & -0.0049 \\
\hline 0.45 & 0.40 & 0.15 & -0.0073 & -0.0083 & -0.0049 & -0.0128 & -0.0144 & -0.0080 & -0.0152 & -0.0170 & -0.0081 \\
\hline 0.50 & 0.40 & 0.10 & -0.0081 & -0.0092 & -0.0062 & -0.0145 & -0.0164 & -0.0106 & -0.0177 & -0.0202 & -0.0118 \\
\hline
\end{tabular}




\section{Remarks}

The connections between the present analysis and related literature can be summarized as follows. Mourmouras (1993) uses the basic model of section 2 (with $\delta=0$ ) to show that competition may lead to overexploitation of privately-owned renewable resources, and describes a set of conservationist policies implementing the Rawlsian optimum. A first difference is the aim of the present analysis: our focus is the existence of situations where agents prefer transfers to laissez-faire for purely selfish reasons, without assuming a predetermined social objective. Second, we have studied individual payoffs in a regime-contingent formulation in order to investigate under what technological and institutional circumstances agents would agree on a higher rate of natural preservation. Third, we have extended the model to include technical progress, monopoly rents, and $R \& D$ activity, obtaining new insights about the intensity of the welfare effects induced by a higher degree of resource preservation. ${ }^{22}$

In the literature on resource economics, intergenerational transfers are also considered by Howarth (1991) and Gerlagh and Keyzer (2001, 2003). In Howarth (1991), uncertainty about states of nature implies that the competitive equilibrium may be inefficient: considering a max-min welfare criterion, Howarth (1991) shows that an optimal scheme of intergenerational transfers allows the economy to obtain intergenerational fairness while restoring efficiency. Gerlagh and Keyzer (2001) consider a production economy where the resource stock has a positive amenity value, and show that a 'trust fund' policy, where future generations receive claims for the natural resource, ensures efficiency and protects the welfare of all generations. In a similar model, Gerlagh and Keyzer (2003) show that conservationist measures may implement optimal allocations that would not be achieved through competitive markets. The common merit of these contributions is to show that fairness may be achieved through policies that also preserve efficiency, in line with the view that intergenerational equity and intertemporal efficiency are distinct, and not necessarily conflicting, objectives (Howarth and Norgaard, 1990). ${ }^{23}$ As noted in the Introduction, this view is not challenged by the present analysis, which - apart from substantial differences in the underlying models ${ }^{24}$ - focuses on the different

while it would not be in the economy with monopoly rents $\left(\Phi^{M}=0.0002\right.$ with $\mu=0.7)$.

22 All the above differences also apply with respect to Krautkraemer and Batina (1999), where the basic model is extended to include a stock-dependent rate of resource regeneration.

${ }^{23}$ Related approaches to fiscal policy with overlapping generations are also present in the literature on environmental degradation. Marini and Scaramozzino (1995) consider pollution externalities and derive the optimal abatement program under the Calvo-Obstfeld criterion for intergenerational equity. In a similar model, Bovenberg and Heijdra (1998) show that public debt policy can be used to redistribute in a 'fair' manner across generations the burden of taxation implied by efficient public abatement.

${ }^{24}$ With respect to the present analysis, important differences are represented by uncertainty (which plays a crucial role in Howarth, 1991) and non-essentiality of 
issue of individual motives for supporting resource-saving policies. The fact that, in the present model, a first-best policy features an implicit redistribution of property rights across generations is in line with the main findings of Gerlagh and Keyzer (2001, 2003).

Emphasizing the role of selfish behavior, our analysis is close to the view that intergenerational exchange need not be linked to parental altruism, as recently argued by Boldrin and Rustichini (2000) and Rangel (2003). The general question asked by these authors is: why should present generations invest in assets that are valuable only to future ones? Boldrin and Rustichini (2000) and Rangel (2003) use game-theoretical arguments to show that intergenerational transfers may arise as voting equilibria when dynastic altruism is absent. ${ }^{25}$ In particular, Boldrin and Rustichini (2000) show that pay-as-you-go social security can be voted into existence by the majority, because the reduction in current saving implied by taxation raises future returns on capital, thus compensating for the negative effect of pension financing. Recalling Proposition 3, our main result hinges on a different mechanism: the reduction in the rate of extraction implied by resource-saving transfers improves production possibilities in the future, and the positive effect on second-period income more than compensates for the negative effect of taxation (provided that resource productivity is sufficiently high).

With respect to models of social security, the opposite direction of transfers in the present analysis (old-to-young) implies substantial differences also from a policymaking perspective, since commitment technologies change. A social security system is supported only if young generations believe that they will receive second-period transfers (Browning, 1975), and this generally requires an intergenerational commitment device - i.e. an institutional arrangement that binds generations yet to be born; in the literature on social security, this device takes various forms, such as social contracts (Hammond, 1975; Sjoblom, 1985), reputational mechanisms (Kotlikoff et al., 1988; Cooley and Soares, 1998), or constitutional norms (Azariadis and Galasso, 2002). Resource-saving policies, instead, are supported when young individuals who receive subsidies accept to pay second-period taxes: this requires an intertemporal commitment device that binds a given generation in the subsequent period, such as lifetime contracts (section 3.3). Further differences with respect to the social security literature arise, as shown in section 3.4, in the context of sequential voting games due to the particular configuration of payoffs in our model.

the resource for producing output - which allows Gerlagh and Keyzer (2001) to consider zero-extraction paths with positive output, a possibility that is ruled out in our model.

${ }^{25}$ Rangel (2003) shows that positive expenditures in goods that only benefit the elderly (such as social security) are necessary to achieve an equilibrium with efficient investment in goods that benefit future generations (such as clean environment and education). 


\section{Conclusions}

This paper analyzed the welfare properties of distortionary transfers in a growth model with overlapping generations and privately owned natural capital. In this framework, unsustainability and resource depletion are a likely outcome of excessive competition, and implementing father-to-son transfers generates a higher degree of resource preservation. The main result is that all newborn agents prefer distortionary intergenerational transfers in both periods of life to persistent laissez-faire conditions, provided that the resource share exceeds a critical threshold level. The reason is that the reduction in the rate of depletion implied by transfers improves production possibilities in the future: if resource productivity is relatively high, the positive effect on second-period output more than compensates (in welfare terms) for the negative effect of taxation. This mechanism is enhanced by the presence of other assets in addition to natural capital. Extending the model to include man-made capital, monopoly rents and R\&D sectors, it is shown that the critical condition becomes less restrictive because the returns from these assets also benefit from the positive growth effect induced by a higher degree of preservation.

The welfare time-path implied by resource-saving policies is not Pareto comparable with that obtained under laissez-faire, because resource owners at time zero suffer a welfare loss due to taxation of the initial stock. The private desire for resource-saving policies unfolds only if agents are either subject to credible pre-commitment, or induced to cooperate with adjacent generations. In the first regard, a succession of lifetime contracts would allow a central authority to implement resource-saving policies in the indefinite future: if young agents are asked to choose between permanent transfers and permanent laissez-faire, the former option is strictly preferred. In a sequential-choice context, the lack of intergenerational cooperation implies that alternative commitment devices must be set, e.g. in the form of positive costs of regime-switching. In both cases, agents support resourcesaving policies for purely selfish reasons, and a paternalistic action is required at time zero. These two features recall the logic of intergenerational transfers à la Gale (1973): if the first resource owner partially renounces his claim over initial endowments, the transmission of this credit forward in time yields welfare gains for all successive generations.

\section{References}

Azariadis, C. and V. Galasso (2002), 'Fiscal constitutions', Journal of Economic Theory 103: 255-281.

Barro, R.J. and X. Sala-i-Martin (2004), Economic Growth, Cambridge MA: MIT Press. Boldrin, M. and A. Rustichini (2000), 'Political equilibria with social security', Review of Economic Dynamics 3: 41-78.

Bovenberg, A.L. and B.J. Heijdra (1998), 'Environmental tax policy and intergenerational distribution', Journal of Public Economics 67: 1-24.

Bromley, D.W. (1990), 'The ideology of efficiency: searching for a theory of policy analysis', Journal of Environmental Economics and Management 19: 86-107.

Browning, E. (1975), 'Why the social insurance budget is too large in a democracy', Economic Inquiry 13: 373-388. 
Cooley, T.F. and J. Soares (1998), 'A positive theory of Social Security based on reputation', Journal of Political Economy 107: 135-160.

Gale, D. (1973), 'Pure exchange equilibrium in dynamic economic models', Journal of Economic Theory 6: 12-36.

Gerlagh R. and M.A. Keyzer (2001), 'Sustainability and the intergenerational distribution of natural resource entitlements', Journal of Public Economics 79: 315341.

Gerlagh R. and M.A. Keyzer (2003), 'Efficiency of conservationist measures: an optimist viewpoint', Journal of Environmental Economics and Management 46: 310333.

Hammond, P. (1975), 'Charity: altruism or cooperative egoism?', in E.S. Phelps (ed.), Altruism, Morality and Economic Theory, New York: Russell Sage Foundation.

Hotelling, H. (1931), 'The economics of exhaustible resources', Journal of Political Economy 39: 137-175.

Howarth, R.B. (1991), 'Intergenerational competitive equilibria under technological uncertainty and an exhaustible resource constraint', Journal of Environmental Economics and Management 21: 225-243.

Howarth, R.B. and R.B. Norgaard (1990), 'Intergenerational resource rights, efficiency, and social optimality', Land Economics 66: 1-11.

Kotlikoff, L.J., T. Persson, and L. Svensson (1988), 'Social contracts as assets: a possible solution to the time-consistency problem', American Economic Review 78: 662-677.

Krautkraemer, J.A. and R.G. Batina (1999), 'On sustainability and intergenerational transfers with a renewable resource', Land Economics 75: 167-184.

Marini, G. and P. Scaramozzino (1995), 'Overlapping generations and environmental control', Journal of Environmental Economics and Management 29: 64-77.

Mourmouras, A. (1993), 'Conservationist government policies and intergenerational equity in an overlapping generations model with renewable resources', Journal of Public Economics 51: 249-268.

Pezzey, J.C.V. (1992), Sustainable Development Concepts: An Economic Analysis, Washington DC: The World Bank.

Pezzey, J.C.V. (1997), 'Sustainability constraints versus "optimality" versus intertemporal concern, and axioms versus data', Land Economics 73: 448-466.

Rangel, A. (2003), 'Forward and backward intergenerational goods: why is social security good for the environment?', American Economic Review 93: 813-834.

Sjoblom, K. (1985), 'Voting for social security', Public Choice 45: 225-240.

Toman, M.A. (1987), 'Existence and optimality of dynamic competitive equilibria with a non-renewable resource', Resource and Energy Economics 9: 1-19.

Valente, S. (2005), 'Sustainable development, renewable resources and technological progress', Environmental and Resource Economics 30: 115-125.

Valente, S. (2006), 'Intergenerational transfers, lifetime welfare and resource preservation: mathematical appendix'. Center of Economic Research, ETH Zurich. Available from www.cer.ethz.ch/resec/people/svalente. 